\title{
A standardized approach to treat complex aortic valve endocarditis: a case series
}

\author{
Anna Gomes ${ }^{1 *}$, Jayant S. Jainandunsing ${ }^{2}$, Sander van Assen ${ }^{3}$, Peter Paul van Geel ${ }^{4}$, Bhanu Sinha', \\ Sandro Gelsomino ${ }^{5}$, Daniel M. Johnson ${ }^{5}$ and Ehsan Natour ${ }^{5,6}$
}

\begin{abstract}
Background: Surgical treatment of complicated aortic valve endocarditis often is challenging, even for experienced surgeons. We aim at demonstrating a standardized surgical approach by stentless bioprostheses for the treatment of aortic valve endocarditis complicated by paravalvular abscess formation.

Methods: Sixteen patients presenting with aortic valve endocarditis ( 4 native and 12 prosthetic valves) and paravalvular abscess formation at various localizations and to different extents were treated by a standardized approach using stentless bioprostheses. The procedure consisted of thorough debridement, root replacement with reimplantation of the coronary arteries and correction of accompanying pathologies (aortoventricular and aortomitral dehiscence, septum derangements, Gerbode defect, total atrioventricular conduction block, mitral and tricuspid valve involvement).

Results: All highly complex patients included (14 males and 2 females; median age 63 years [range 31-77]) could be successfully treated with stentless bioprostheses as aortic root replacement. Radical surgical debridement of infected tissue with anatomical recontruction was feasible. Although predicted operative mortality was high (median logarithmic EuroSCORE I of 40.7 [range 12.8-68.3]), in-hospital and 30-day mortality rates were favorable (18.8 and $12.5 \%$ respectively).

Conclusions: Repair of active aortic valve endocarditis complicated by paravalvular abscess formation and destruction of the left ventricular outflow tract with stentless bioprosthesis is a valuable option for both native and prosthetic valves. It presents a standardized approach with a high success rate for complete debridement, is readily available, and yields comparable clinical outcomes to the historical gold standard, repair by homografts. Additionally, use of one type of prosthesis reduces logistical issues and purchasing costs.
\end{abstract}

Keywords: Infective endocarditis, Stentless bioprostheses, Abscess, High-risk, Surgery

\section{Background}

Infective endocarditis causes in-hospital mortality of $20 \%$ and $40 \%$ after 1-year, rising further to $79 \%$ for aortic valve endocarditis $[1,2]$. This high rate is largely due to extended local destruction of heart tissue, e.g. paravalvular abscess formation, with secondary heart failure. Risk factors for endocarditis include rheumatic, congenital, and degenerative valve lesions, intracardiac prosthetic material, intravenous drug use, and healthcare contact [3]. Diagnosis of endocarditis is based on the modified

\footnotetext{
* Correspondence: a.gomes@umcg.nl

${ }^{1}$ Department of Medical Microbiology, University of Groningen, University Medical Center Groningen, Groningen, Netherlands

Full list of author information is available at the end of the article
}

Duke criteria, bearing a sensitivity and specificity of $80 \%$ for the total patient population [4]. As this is not optimal, the expert opinion of a multidisciplinairy team is essential for diagnosis. Therapy of endocarditis relies on antimicrobial therapy and surgery for cardiac anatomical damage (vegetation, abscess, fistula, shrunken valve, valve tears or holes, prosthetic valve detachment), as well as uncontrolled infection. In this way, $25-50 \%$ of patients are operated upon in the acute phase of infection and an additional $20-40 \%$ later in the course due to haemodynamic complications [5].

Paravalvular abscess formation complicates aortic valve endocarditis. Early surgical treatment of complicated endocarditis improves outcome when compared to

(c) The Author(s). 2018 Open Access This article is distributed under the terms of the Creative Commons Attribution 4.0 International License (http://creativecommons.org/licenses/by/4.0/), which permits unrestricted use, distribution, and 
medical therapy alone, reducing 6-month mortality from 33 to $16 \%$ [6] and the composite endpoint of death/ embolic events/ recurrence of endocarditis from 28 to 3\% [7]. Aortic valve paravalvular abscess formation and root destruction requires radical resection of infected tissue with subsequent reconstruction of the left ventricular outflow tract (LVOT) (modified Bentall procedure) [8]. Therefore, surgical treatment of complicated aortic valve endocarditis is considered challenging, bearing high operative (11-40\% in-hospital) and late (60\% in 5 years) mortality rates [9].

Various surgical techniques are used to treat complicated aortic valve endocarditis, depending on the surgical preference and with differing results: patch, prosthesis, homograft. Historically, cryopreserved homografts were considered as the gold standard for these patients [10-12]. Homografts offer low recurrence rates, acceptable valve-related morbidity and mortality, and their low transvalvular gradient is associated with improved left ventricular mass regression [13, 14]. Homografts also have disadvantages, including demanding surgical techniques, the need for reoperation due to calcification, limited availability and shelf life $[8,9,15]$. Nowadays, biological stentless valves are more often used in complicated aortic valve endocarditis $[8,9]$. Using these prostheses, the surgical versatility of homografts is reached due to their comparable durability, shape and pliability [8]. In addition, stentless bioprostheses have advantages, such as a rather long shelf life and being readily available in various sizes, uniform in quality, technically easier to implant and furnished with anticalcification properties $[8,13,14,16-18]$.

Guidelines support the use of both homografts and stentless bioprostheses in aortic valve endocarditis with paravalvular abscess formation [2, 10, 19]. The choice of prosthesis depends on patient characteristics, technical considerations, and surgeon preferences $[8,14]$. In this illustrated series of sixteen patients with aortic valve endocarditis and complicating paravalvular abscess formation, we show that the use of stentless bioprostheses provides a more standardized surgical procedure that consists of thorough debridement, root replacement with reimplantation of the coronary arteries, and treatment of accompanying pathologies.

\section{Methods}

\section{Patients}

In this case series we aimed at providing evidence for the standardized use of a stentless bioprostheses in complex aortic valve endocarditis. "Standardized use" refers to the use of one type of stentless bioprosthesis for a variety of anatomical problems complicating aortic valve endocarditis. Clinical data and high quality macroscopic pictures from sixteen patients with active aortic valve endocarditis and paravalvular abscess formation were collected between 2006 and 2015. In this time period, a total of 85 patients underwent aortic valve surgery for endocarditis in our center. Here, we report on those patients treated with stentless bioprostheses. Their endocarditis was not limited to the cusps but also involved the annulus with formation of large paravalvular abscesses at various anatomical locations. Consequently, complications arose, such as root disarrangement with loss of aortaventricular or aortomitral continuity, atrioventricular conduction disturbance, or infection of the septum or the right ventricle. Despite their poor clinical condition, these patients were deemed eligibile for surgical valve repair and LVOT reconstruction using stentless bioprostheses.

\section{Definitions}

Infective endocarditis was diagnosed based on the modified Duke criteria [4] and expert opinion of a multidisciplinairy team. Prosthetic valve endocarditis was considered early if it occurred during the first year after valve replacement, otherwise it was considered late [2]. Causative microorganisms were identified by culture and molecular testing on peripheral blood and tissue or prosthetic material collected during surgery [2]. Functional cardiac derangements as described by the guidelines were important indications for surgery $[2,19]$. Macroscopically visible pathological findings considered an indication for the use of stentless bioprostheses were presence of destructive lesions, including annular abscess, paravalvular leak and cusp perforation. Re-thoracotomy was defined as reopening of the sternum after implantation of the bioprosthesis. Reoperation was defined as any surgical procedure involving the implanted bioprosthesis. Recurrence was used as a combined term for both relapse (repeat episodes of endocarditis caused by the same microorganism) and reinfection (infection caused by a different microorganism) [2].

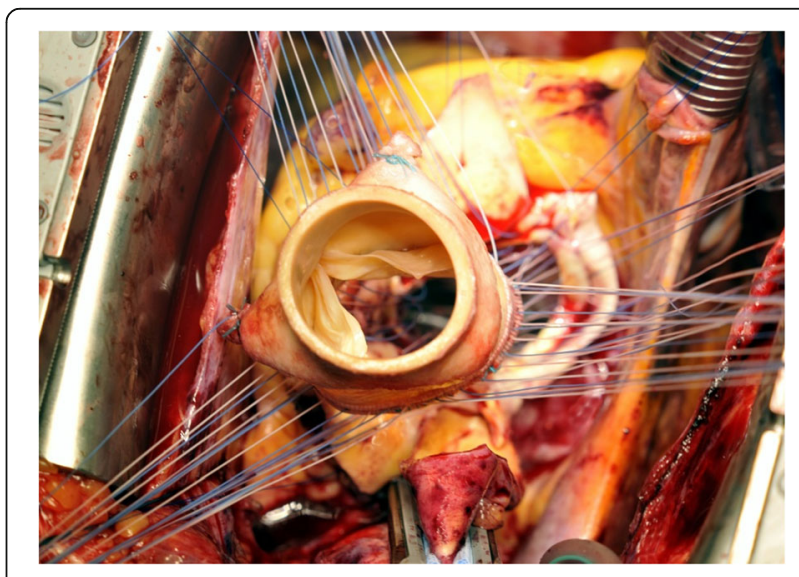

Fig. 1 Stentless bioprosthesis 


\section{Prosthesis}

The Freestyle ${ }^{\oplus}$ bioprosthesis (Medtronic Inc., Minneapolis, MN, USA) is a stentless porcine aortic root prosthesis with ligated coronary arteries and a thin skirt over the porcine septal myocardium. The bioprosthesis is fixed with low pressure applied to the aortic wall, and zero-net pressure across the leaflets (Fig. 1). Pre-implantation, the bioprosthesis underwent an anticalcification treatment using alpha-amino-oleic acid. The device can be implanted by various techniques: subcoronary valve replacement, root inclusion, or complete aortic root replacement.

\section{Surgical technique}

The standard surgical approach was a median (re)sternotomy with mild/moderate hypothermic $\left(32-34{ }^{\circ} \mathrm{C}\right)$ cardiopulmonary bypass and cardioplegic cardiac arrest (retrograde blood cardioplegia). Cardiopulmonary bypass was performed using aortic cannulation and right atrial or bicaval cannulation for venous drainage.

The aorta was transected above the sinotubular junction. After the aortotomy exposure, the abscess regions were inspected (Fig. 2) and infected native cusps or prosthesis as well as any aortic aneurysms were removed with extensive tissue debridement. The aortic sinuses were resected with
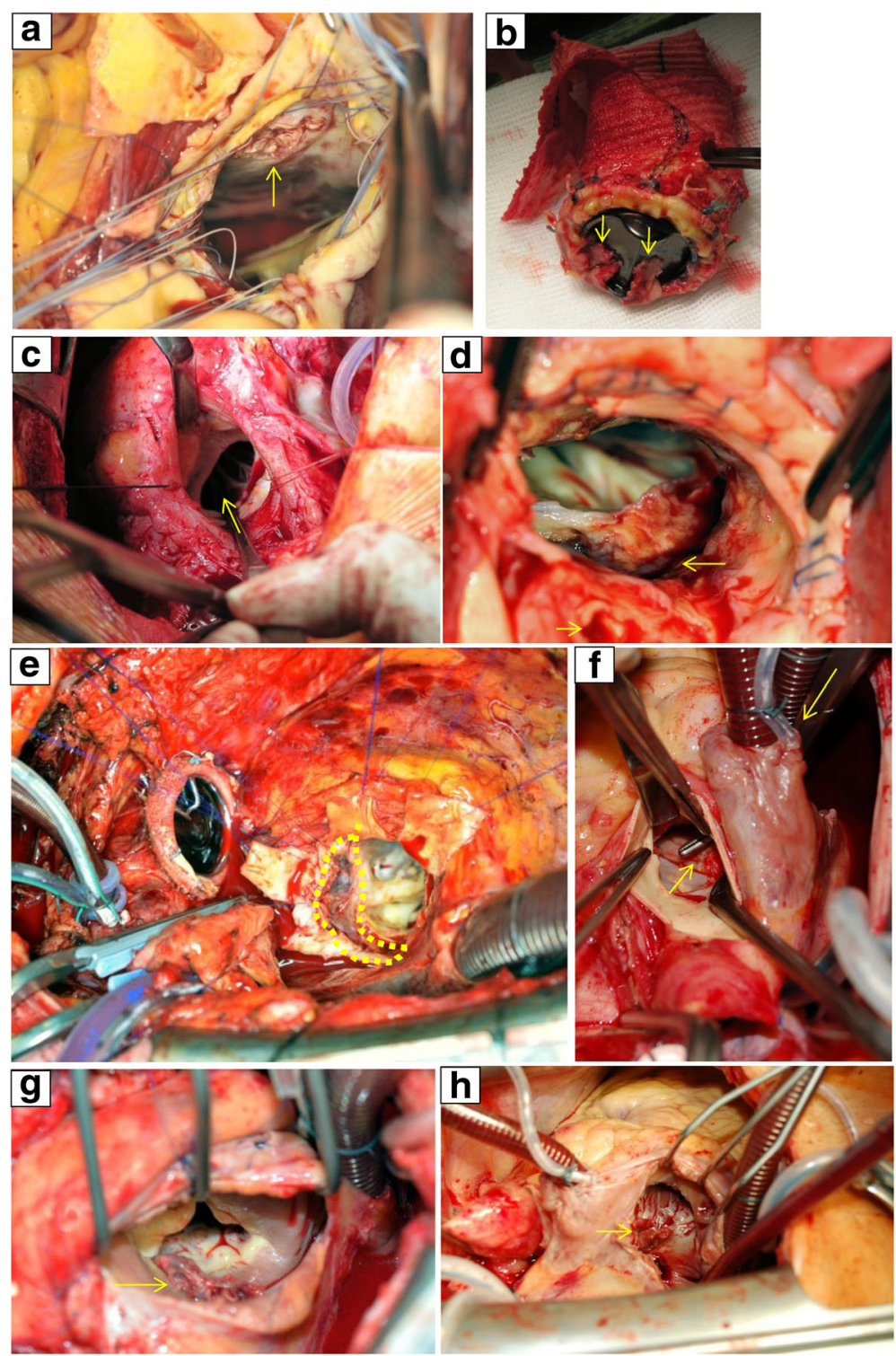

Fig. 2 Aortic valve endocarditis with paravalvular abscess formation, surgical view: a view from aortic root, ventricular septal defect, b valved conduit with vegetations, c total aorto-ventricular dehiscence, with left ventricular outflow tract discontinuity, $\mathbf{d}$ abscess cavity (large arrow) with left main coronary visible (small arrow), e retro-aortal abscess cavity with aorto-mitral involvement and mitral annulus dehiscence, $\mathbf{f}$ aorto-atrial fistula, Gerbode-like defect, $\mathbf{g}$ atrial view, tricuspid valve annular abscess with torn septal leaflet and paravalvular leak, $\mathbf{h}$ tricuspid valve deformity with vegetational mass 
trumpet-shaped recesses of the coronary ostia. More specifically, a ventricular septum defect just under the membranous septum was identified in Fig. 2a. In this case a pericardial patch was used, which was distally sutured on the septum covering both the defect and the membranous septum, proximally attached at the level of the aortic annulus. Figure $2 \mathrm{~b}$ and $\mathrm{c}$ depict chronic dehiscence of a mechanical prosthesis (implanted after a Bentall procedure) as a result of abcess formation at the annular level. Interestingly, the prosthesis was found floating above the annulus, only attached by the coronary arteries. Hence, the adhesions surrounding the annulus kept the prosthesis in place. Following resection of the infected prosthesis and clearance of the abcess, the stentless bioprosthesis was sutured on the annulus using a single-stitch technique. Given the chronic nature of disease in this case, the bioprosthesis was parachutted downwards towars the subannular plane to minimize traction of the chronically anchored anterior mitral leaflet (AML). In contrast, Fig. $2 \mathrm{~d}$ and e illustrate acute subannular abcess formation. In this case, the AML was detached from the annulus while the prosthesis attachment site remained intact. In this case, due to the recent onset of infection, traction of the AML to the annulus plane and a neo-annulus were created after clearance of the abcess and other inflammatory tissue. Afterwards the stentless bioprosthesis was sutured to the annulus. Figure $2 \mathrm{f}$ to $\mathrm{h}$ depict Gerbode lesions with tricuspid valve involvement. Gerbode(-like) lesions encompass fistulas formed between the left ventricle(aorta) and the right side of the heart, appearing above or below the septal leaflet of the tricuspid valve. Repair of the subvalvular fistula from the right side included temporary resection of the spetal leaflet of the tricupid valve, which was thereafter re-attached.

After debridement, restoration and sizing of the aortic annulus the proximal anastomosis was performed using 20-25 interrupted sutures of Ticron 3-0 in a single plane. If required, the coronary ostia were mobilised using diathermy. After completion of the proximal suture line, the patient's coronary ostia were reimplanted end-to-side to the corresponding sinus of Valsalva of the prosthesis using a continuous 5-0 polyproylene suture. Finally, the bioprosthesis was anastomosed with the aorta using continuous 4-0 polyproylene. If further resection of the ascending aorta was required, a vascular tube graft was interposed.

\section{Ethical considerations}

The institutional medical ethical review board of the University Medical Center Groningen approved the use of retrospective patient data for our study and waived informed consent (METc2015/033; February 2015).

\section{Results}

\section{Patient characteristics}

This series consecutively included 14 males and 2 females with a median age of 63 years (Tables 1 and 2). All patients had an urgent indication for cardiothoracic surgery with implantation of a stentless bioprosthesis as root replacement due to uncontrolled infection and abscess formation (evidence class I and level B [2]). Median New York Heart Association score was III, and median logarithmic EuroSCORE I score was 40.7. Median follow-up for survivors was 4.6 years. All survivors were followed for at least 2 years, $36 \%$ were followed for 5 years, and $9 \%$ for 10 or more years. In 4 patients $(25 \%)$ the endocarditis involved native aortic valves, with 2 identified bicuspid valves. In 12 patients (58\%) the endocarditis involved prosthetic aortic valves: in 7 patients the aortic valve was replaced once and in 1 patient twice before, in 5 patients a Bentall procedure had been

Table 1 Patient characteristics $(n=16$

\begin{tabular}{|c|c|}
\hline Characteristic & Value \\
\hline Age: median [range] (years) & $63[31-77]$ \\
\hline Gender: male; female, n (\%) & $14(87.5) ; 2(12.5)$ \\
\hline Reoperation / PVE (\%) & 75 \\
\hline Follow-up survivors: median [range] (years) & $4.6[2.3-11.7]$ \\
\hline NYHA score: median [range] & III [II-IV] \\
\hline Logarithmic EuroSCORE I: median [range] & $40.7[12.8-68.3]$ \\
\hline \multicolumn{2}{|l|}{ Microbiology } \\
\hline \multicolumn{2}{|l|}{$P V E$} \\
\hline $\begin{array}{l}\text { - Staphylococcus spp.: } 5 \text { CoNS, } \\
1 \text { S. aureus }\end{array}$ & $n=6(50 \%)$ \\
\hline $\begin{array}{l}\text { - Streptococcus spp.: } 1 \text { viridans group, } \\
1 \text { S. bovis, } 1 \text { S. agalactiae }\end{array}$ & $n=3(25 \%)$ \\
\hline - Enterococcus spp.: 2 E. faecalis & $n=2(17 \%)$ \\
\hline - no micro-organism identified & $n=1(8 \%)$ \\
\hline \multicolumn{2}{|l|}{ NVE } \\
\hline - Staphylococcus spp.: S. aureus & $n=1(25 \%)$ \\
\hline - Streptococcus spp.: 2 viridans group & $n=2(50 \%)$ \\
\hline - Enterococcus spp.: E. faecalis & $n=1(25 \%)$ \\
\hline Outcome & Value \\
\hline $\begin{array}{l}\text { Cardiopulmonary bypass perfusion time: } \\
\text { median [range] (minutes) }\end{array}$ & $358[186-731]$ \\
\hline $\begin{array}{l}\text { Aortic cross-clamping time: median [range] } \\
\text { (minutes) }\end{array}$ & 266 [107-389] \\
\hline Intensive care unit stay: median [range] (days) & $1.5[1-21]$ \\
\hline Hospital stay: median [range] (days) & 55 [29-90] \\
\hline In-hospital mortality: n (\%) & $3(18.8)$ \\
\hline 30 day mortality: n (\%) & $2(12.5)$ \\
\hline
\end{tabular}

CoNS coagulase negative staphylococci, COPD chronic obstructive pulmonary disease, e.c.i. e cause ignota, NVE native valve endocarditis, NYHA New York Heart Association, PVE prosthetic valve endocarditis, SD standard deviation 
Table 2 Characteristics of included patients

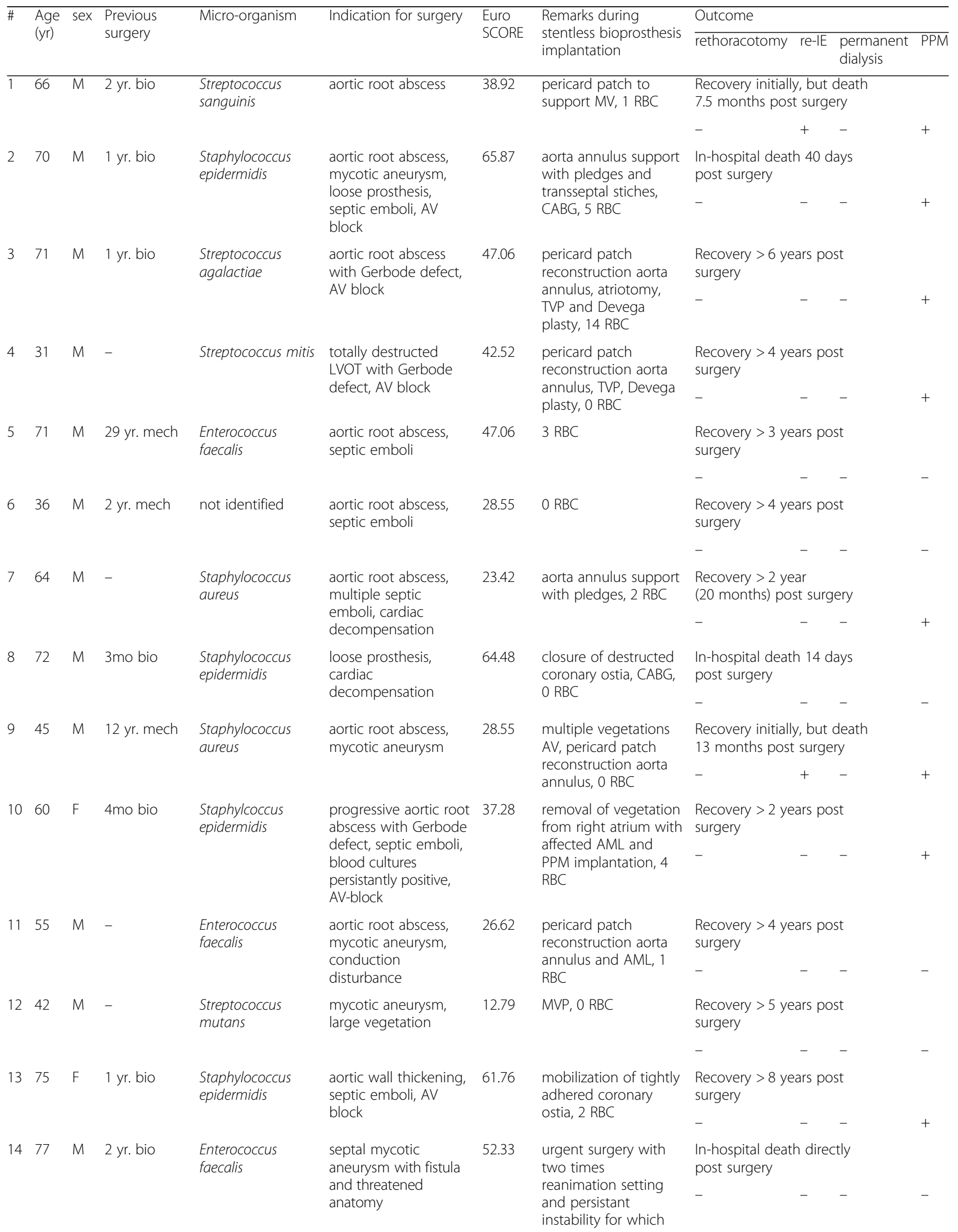


Table 2 Characteristics of included patients (Continued)

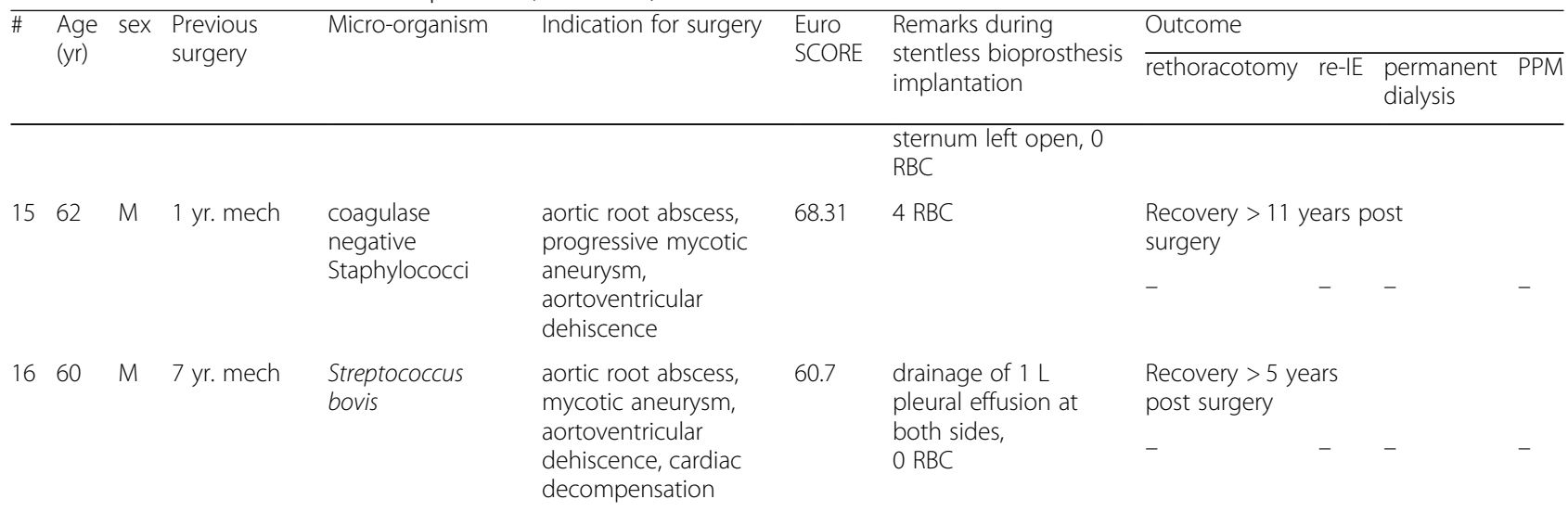

\# patient number, $A M L$ anterior mitral leaflet, $A V$ aortic valve, $A V$ block atrio-ventricular block, bio biological prosthetic valve inplanted, $C A B G$ coronary artery bypass grafting, EuroSCORE logarithimic I, $F$ female, $L V O T$ left ventricular outflow tract, $M$ male, mech mechanical prosthetic valve inplanted, mo months, $M V$ mitral valve, PPM placement of permanent pacemaker, RBC number of bags with red blood cells given during surgery, re-IE recurrence of endocarditis, rethoracotomy for bleeding or tamponade, TVP tricuspid valve plasty, yr. years
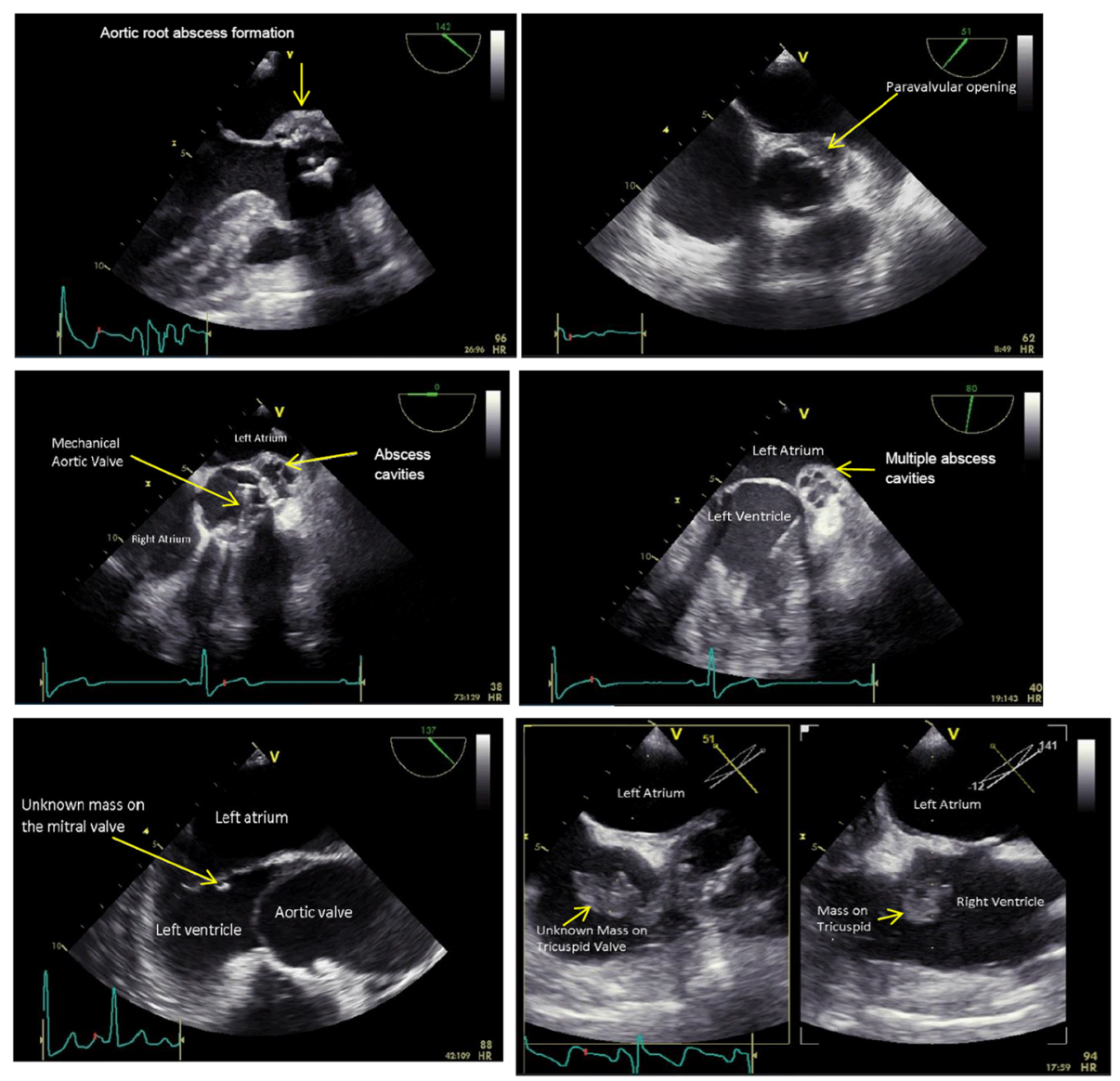

Fig. 3 Aortic valve endocarditis with paravalvular abscess formation, transesophageal echocardiographic view 
performed. Of the patients with prosthetic valves, 2 patients had early (3-4 months after surgery) and 10 patients late endocarditis (1-29 years after surgery). Inhospital and 30 day mortality were $18.8 \%$ and $12.5 \%$, respectively; 2-year recurrence rate was $14 \%$.

Infectious cardiac anatomical compliations eligible for stentless bioprostheses repair

Several situations of active aortic valve endocarditis with paravalvular abscess formation and accompanying pathologies were deemed eligible for valve repair and LVOT reconstruction with a stentless bioprosthesis (Figs. 2, 3, 4 and 5).

\section{Aortoventricular dehiscence}

Seven patients with a prosthetic valve presented with aortoventricular dehiscence. Pathogens included coagulase-negative staphylococci, Staphylococcus aureus, Streptococcus bovis, Enterococcus faecalis. 29\% (2/7) of these patients also had extention of infection towards their mitral valve.

\section{Septum derangements}

Seven patients presented with infectious derangements of their septum, including vegetations and perforations. Four of these patients had a prosthetic valve. Pathogens included Staphylococcus epidermidis, Staphylococcus aureus, Streptococcus agalactiae, Streptococcus mitis, and Enterococcus faecalis. 71\% (5/7) of these patients had a permanent pacemaker (PPM) implanted and $43 \%$
(3/7) had extention of infection towards the right side of the heart through a Gerbode(-like) defect.

\section{Total atrioventricular conduction block}

Six patients presented with a total or third degree atrioventricular conduction block. Five of these patients had a prosthetic valve. Pathogens included Staphylococcus epidermidis, Streptococcus sanguinis, Streptococcus agalactiae, and Streptococcus mitis. All these patients had a PPM implanted, $50 \%$ had extention of infection towards their right ventricle through a Gerbode(-like) defect, and 50\% had extention of infection towards their mitral valve.

\section{Gerbode defect (with tricuspid valve involvement)}

Three patients presented with a Gerbode(-like) defect, a left ventricular (aorta) to right atrial shunt [20], causing an infection of their tricuspid valve due to local spread. Two of these patients had a prosthetic valve. Pathogens included Staphylococcus epidermidis, Streptococcus agalactiae and Streptococcus mitis. All patients had a PPM implanted, and needed a tricuspid valve plasty.

\section{Mitral valve involvement (with aortomitral dehiscence)}

Seven patients presented with extension of infection towards their mitral valve. Five of these patients had a prosthetic valve. Pathogens included Staphylococcus epidermidis, Streptococcus sanguinis, Streptococcus mutans, and Enterococcus faecalis. 57\% (4/7) of these patients had septic emboli.
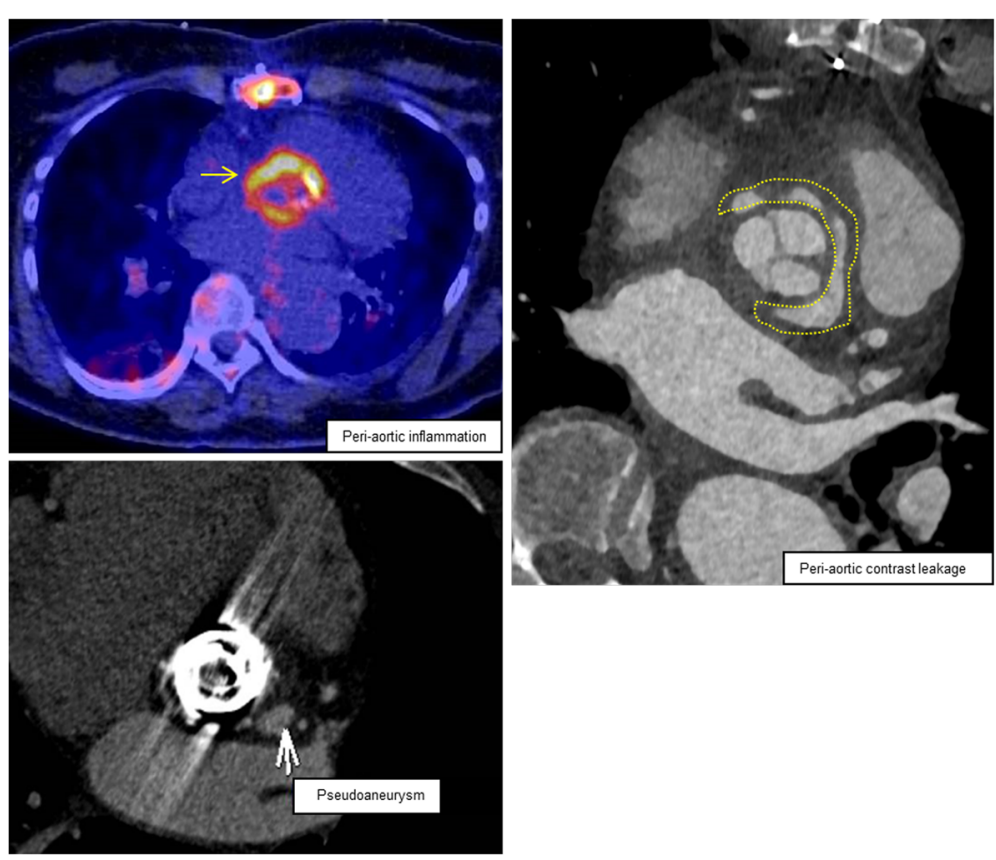

Fig. 4 Aortic valve endocarditis with paravalvular abscess formation, nuclear/radiological view with ${ }^{18} \mathrm{~F}$-fluorodeoxyglucose positron emission tomography/computed tomography 


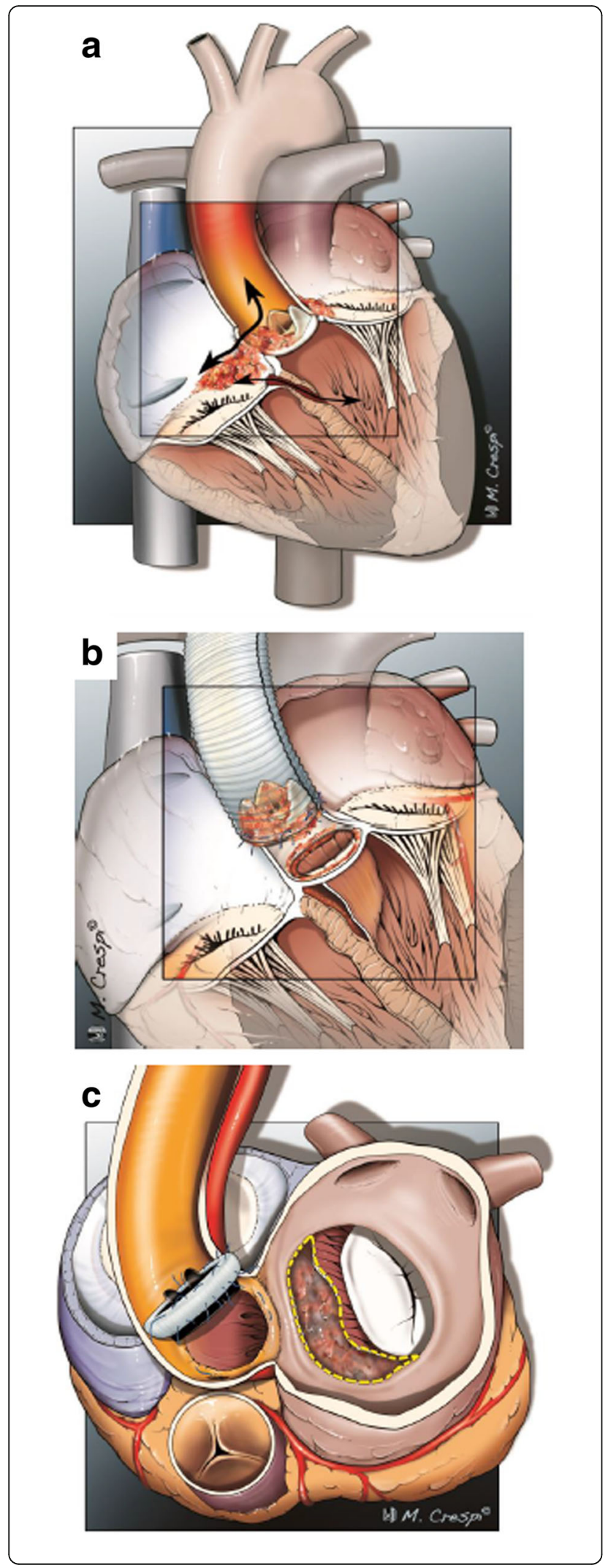

Fig. 5 Aortic valve endocarditis with paravalvular abscess formation, illustrations: a coronal view on the heart showing a ventricular septum defect, Gerbode defect (communication between the left ventricle and the right atrium), Gerbode-like defect (communication between the aorta and the right atrium) and tricuspid valve deformity; $\mathbf{b}$ coronal view on the proximal heart showing total aorto-ventricular dehiscence; c horizontal view on the proximal heart showing a retro-aortal abscess cavity with aorto-mitral involvement and mitral annulus dehiscence

\section{Extracardiac complications due to endocarditis}

Infective endocarditis is a cardiac disease with extracardiac complications due to hematogenous and embolic spread. In our series, the three most common complications were: mycotic aneurysm $(n=3)$, cerebral emboli $(n=2)$, and vertebral osteomyelitis $(n=2)$.

\section{Patient survival}

Figure 6 shows the survival of included patients for 11 years. Five patients died during this period (Table 2), due to: end-stage heart failure 227 days post-surgery; recurrent respiratory insufficiency resulting from sputum retention, encephalopathy and extended postoperative wound infection 40 days post-surgery; active intracerebral bleeding without therapeutic options 14 days post-surgery; re-infection of the prosthesis with cerebral embolization, mediastinitis and kidney failure 388 days post-surgery; severe hemodynamic instability immediately post-surgery.

\section{Discussion}

We have described and illustrated a series of patients with aortic valve endocarditis, paravalvular abscess formation and accompanying pathologies. All patients underwent cardiothoracic surgery with thorough debridement and restoration of cardiac anatomy using stentless bioprostheses. Patients with native and several types of prosthetic valves were included. Pathogens varied, including staphylococci $(n=7)$, streptococci $(n=5)$ and enterococci $(n=3)$. Predicted mortality was high (median logarithmic EuroSCORE I of 40.7 [range 12.8-68.3]) but actual mortality was relatively low (in-hospital 18.8\% [3/16] and 30-day 12.5\% [2/ 16]), showing that the stentless bioprostheses can be successfully used in a variety of surgically challenging situations and allows for a standardized approach. Figures 2, 3 and 4 show the cases of aortic valve endocarditis with various paravalvular abscesses from a surgical (Fig. 2), echocardiographic (Fig. 3) and nuclear/radiological (Fig. 4) view.

Due to its design, it is possible to use the stentless bioprostheses for subcoronary valve replacement, for inclusion of the root, or full root replacement $[13,16]$. Using the prostheses for a full root replacement, enables exclusion of abscess cavities and the rebuilding of the LVOT. Furthermore, it maintains root geometry and the integrity of the "leaflet, sinus and root" as a functional entity, both 
Survival, short-term

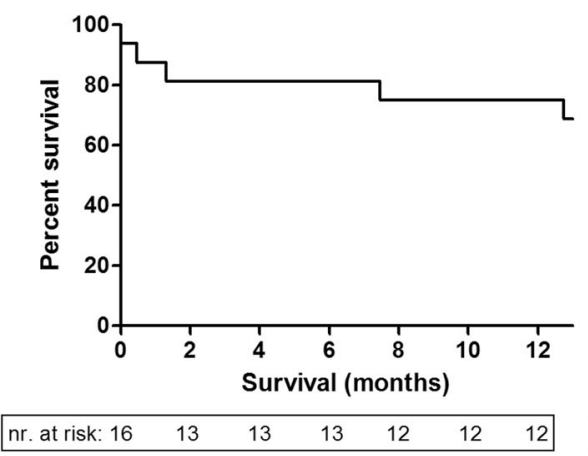

Survival, long-term

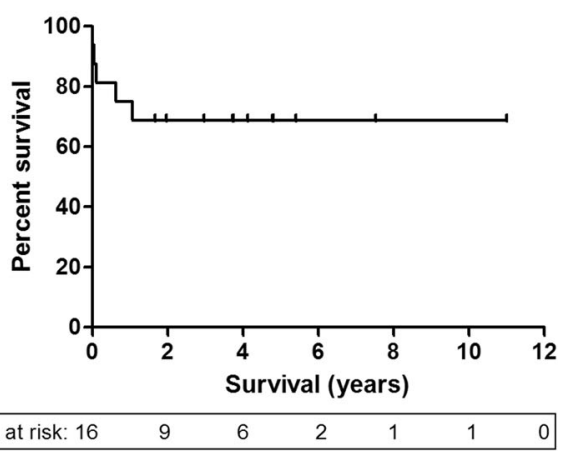

Fig. 6 Kaplan-Meier curves. The short-term curve depicts the survival of included patients over 12 months post surgery and the long-term curve depicts the survival of included patients during the total follow-up time (maximum 11 years)

increasing durability of the bioprostheses $[8,21]$. Implantation with the single suture technique is believed to allow placement of the stentless bioprosthesis as full root replacement without narrowing of the LVOT nor obstruction by any rigid structures such as pledgets [21]. Using the stentless bioprothesis as a full root replacement in complex endocarditis was previously reported in 5 patients [22] and now supported with our data of 16 patients with various well described paravalvular abscesses.

Survival rates for the use of stentless bioprostheses when active native or prosthetic aortic valve endocarditis is complicated by extensive destruction of the LVOT have been reported as $81-89 \%, 76-83 \%, 62-70 \%$, and $54 \%$ at 30 days, 1 year, 5 years, and 10 years, respectively $[8,13,14,16,17]$. Although early mortality remains considerably high in the group presented, studies show that stentless bioprostheses yield clinical outcomes, postoperative echocardiographic data, long-term recurrence and survival rates comparable to those of cryopreserved homografts $[8,9,13,14,16,17]$. Indeed, the recurrence rates of homografts $(3.8-6.8 \%)$ and stentless valves (3.7-8.6\%) are similar and lower than that of standard prostheses (33\%) [13]. However, as compared with standard aortic valve replacement, the need for reimplantation of coronary arteries conveys an increased risk of atrioventricular conduction block. Also, the use of bioprosthesis conveys an increased risk of reoperation in juvenile patients. Even though stentless and stented valves show equal performance with regard to clinical parameters and valve-related mortality, stentless valves have more favorable hemodynamic and biomechanical characteristics and significantly higher long-term survival rates $(78 \%$ versus $66 \%$ in 8 -years) $[8,14,16]$. Compared to homografts, progression of valve dysfunction (37\% versus $86 \%, p<0.01$ ) [23] and need for reoperations are lower for stentless bioprostheses [14, 18, 23]. Furthermore, implantation is less challenging and demanding for stentless bioprostheses and reoperation of a calcified prosthesis may be easier as compared to homografts [9].
A limitation of this study is its retrospective nature. Furthermore, we did not directly compare the Freestyle bioprosthesis with other stentless bioprostheses, nor with homografts. The described patient group had been previously treated with homografts, but we did not consider it useful to compare results from 10 years ago with recent results. Prospective studies should examine durability and long-term valve-related complication free survival of patients treated with various models of stentless bioprostheses. Experience with reoperation for replacing a bioroot also needs further examination [21].

\section{Conclusion}

Aortic valve endocarditis with paravalvular abscess formation remains a therapeutic challenge for which stentless bioprosthesis is a credible surgical option. This prosthesis allows a radical and uniform approach with a good surgical overview and use of limited prosthetic material. It enables successful treatment of complex aortic valve endocarditis with complete debridement, elimination of shunts and anatomical deviations, reconstruction of the LVOT and aortomitral continuity. Stentless bioprostheses yield comparable clinical outcomes as the historical gold standard - the homograft - and are readily available. Of note, use of one type of prosthesis reduces logistical issues and purchasing costs.

\section{Abbreviations \\ AML: Anterior mitral leaflet; LVOT: Left ventricular outflow tract; PPM: Permanent pacemaker}

\section{Acknowledgements}

We thank Jakob Wilkens for the high-quality macroscopic pictures. We thank Andor Glaudemans and Niek Prakken for the FDG-PET and CTA images. We thank Massimiliano Crespi for the illustrations of intracardiac pathology. We thank Igor van der Weide for the total number of aortic valve endocarditis surgeries in our center. We thank Sebastian-Patrick Sommer for valuable discussions.

\section{Funding}

This work was supported by INTERREG project EurHealth-1Health [grant number 202085]; http://www.eurhealth-1health.eu/nl/home/. INTERREG had not intellectual role. 


\section{Availability of data and materials}

All data generated or analysed during this study are included in this published article.

\section{Authors' contributions}

AG composed the report. JJ, SVA, PPVG, BS, SG, DMJ, EN supervised the report. All authors wrote, edited, and reviewed the manuscript. All authors read and approved the final manuscript.

\section{Ethics approval and consent to participate}

The institutional medical ethical review board of the University Medical Center Groningen approved the use of retrospective patient data for our study and waived informed consent (METc2015/033; Februari 13, 2015). Consent to participate was obtained from all included patients.

\section{Consent for publication}

Consent for publication was obtained from all patients from whom the manuscript contains individual personal data.

\section{Competing interests}

The authors declare that they have no competing interests.

\section{Publisher's Note}

Springer Nature remains neutral with regard to jurisdictional claims in published maps and institutional affiliations.

\section{Author details}

'Department of Medical Microbiology, University of Groningen, University Medical Center Groningen, Groningen, Netherlands. ${ }^{2}$ Department of Anesthesiology, University of Groningen, University Medical Center Groningen, Groningen, Netherlands. ${ }^{3}$ Department of Internal Medicine, Infectious Diseases, Treant Care Group, Hoogeveen, Netherlands. ${ }^{4}$ Department of Cardiology, University of Groningen, University Medical Center Groningen, Groningen, Netherlands. ${ }^{5}$ Department of Thoracic Surgery, Maastricht University Medical Center, Maastricht, Netherlands. ${ }^{6}$ Department of Cardio-Thoracic Surgery, University of Groningen, University Medical Center Groningen, Groningen, Netherlands.

Received: 21 December 2017 Accepted: 4 April 2018 Published online: 19 April 2018

\section{References}

1. Murdoch DR, Corey GR, Hoen B, Miro JM, Fowler VG, Jr BAS, et al. Clinical presentation, etiology, and outcome of infective endocarditis in the $21 \mathrm{st}$ century: the international collaboration on endocarditis-prospective cohort study. Arch Intern Med. 2009;169(5):463-73.

2. Habib G, Lancellotti P, Antunes MJ, Bongiorni MG, Casalta JP, Del Zotti F, et al. 2015 ESC guidelines for the management of infective endocarditis: the task force for the management of infective endocarditis of the European Society of Cardiology (ESC). Endorsed by: European Association for CardioThoracic Surgery (EACTS), the European Association of Nuclear Medicine (EANM). Eur Heart J. 2015;36(44):3075-128.

3. Moreillon P, Que YA. Infective endocarditis. Lancet. 2004;363(9403):139-49.

4. Li JS, Sexton DJ, Mick N, Nettles R, Fowler VG, Jr RT, et al. Proposed modifications to the Duke criteria for the diagnosis of infective endocarditis. Clin Infect Dis. 2000;30(4):633-8.

5. Prendergast $B D$, Tornos P. Surgery for infective endocarditis: who and when? Circulation. 2010:121(9):1141-52.

6. Vikram HR, Buenconsejo J, Hasbun R, Quagliarello VJ. Impact of valve surgery on 6-month mortality in adults with complicated, left-sided native valve endocarditis: a propensity analysis. JAMA. 2003;290(24):3207-14.

7. Kang DH, Kim YJ, Kim SH, Sun BJ, Kim DH, Yun SC, et al. Early surgery versus conventional treatment for infective endocarditis. N Engl J Med. 2012; 366(26):2466-73.

8. Schneider AW, Hazekamp MG, Versteegh MI, Bruggemans EF, Holman ER, Klautz RJ, et al. Stentless bioprostheses: a versatile and durable solution in extensive aortic valve endocarditis. Eur J Cardiothorac Surg. 2016;49(6): 1699-704.

9. Sponga S, Daffarra C, Pavoni D, Vendramin I, Mazzaro E, Piani D, et al. Surgical management of destructive aortic endocarditis: left ventricular outflow reconstruction with the Sorin Pericarbon freedom stentless bioprosthesis dagger. Eur J Cardiothorac Surg. 2016;49(1):242-8.

10. Byrne JG, Rezai K, Sanchez JA, Bernstein RA, Okum E, Leacche M, et al. Surgical management of endocarditis: the society of thoracic surgeons clinical practice guideline. Ann Thorac Surg. 2011;91(6):2012-9.

11. Bonow RO, Carabello BA, Chatterjee K, de Leon AC Jr, Faxon DP, Freed MD, et al. 2008 focused update incorporated into the ACC/AHA 2006 guidelines for the management of patients with valvular heart disease: a report of the American College of Cardiology/American Heart Association task force on practice guidelines (writing committee to revise the 1998 guidelines for the management of patients with valvular heart disease). Endorsed by the Society of Cardiovascular Anesthesiologists, Society for Cardiovascular Angiography and Interventions, and Society of Thoracic Surgeons. J Am Coll Cardiol. 2008;52(13):e1-142.

12. Sabik JF, Lytle BW, Blackstone EH, Marullo AG, Pettersson GB, Cosgrove DM. Aortic root replacement with cryopreserved allograft for prosthetic valve endocarditis. Ann Thorac Surg. 2002;74(3):650-9.

13. Perrotta S, Lentini S. In patients with severe active aortic valve endocarditis, is a stentless valve as good as the homograft? Interact Cardiovasc Thorac Surg. 2010;11(3):309-13.

14. Heinz A, Dumfarth J, Ruttmann-Ulmer E, Grimm M, Muller LC. Freestyle root replacement for complex destructive aortic valve endocarditis. J Thorac Cardiovasc Surg. 2014;147(4):1265-70

15. Savage EB, Saha-Chaudhuri P, Asher CR, Brennan JM, Gammie JS. Outcomes and prosthesis choice for active aortic valve infective endocarditis: analysis of the Society of Thoracic Surgeons adult cardiac surgery database. Ann Thorac Surg. 2014;98(3):806-14.

16. Miceli A, Croccia M, Simeoni S, Varone E, Murzi M, Farneti PA, et al. Root replacement with stentless freestyle bioprostheses for active endocarditis: a single Centre experience. Interact Cardiovasc Thorac Surg. 2013;16(1):27-30.

17. Edlin P, Sartipy U. Freestyle xenograft for aortic valve endocarditis. J Thorac Cardiovasc Surg. 2014;147(1):542-3.

18. El-Hamamsy I, Clark L, Stevens LM, Sarang Z, Melina G, Takkenberg JJ, et al. Late outcomes following freestyle versus homograft aortic root replacement: results from a prospective randomized trial. J Am Coll Cardiol. 2010;55(4):368-76

19. Nishimura RA, Otto CM, Bonow RO, Carabello BA, Erwin JP 3rd, Guyton RA, et al. 2014 AHA/ACC guideline for the management of patients with valvular heart disease: a report of the American College of Cardiology/ American Heart Association task force on practice guidelines. J Am Coll Cardiol. 2014;63(22):e57-185.

20. Davies A, Lai K, Bastian B. Acquired Gerbode defects associated with infective endocarditis. Heart Lung Circ. 2016;25(3):e59-61.

21. Dapunt OE, Easo J, Holzl PP, Murin P, Sudkamp M, Horst M, et al. Stentless full root bioprosthesis in surgery for complex aortic valve-ascending aortic disease: a single center experience of over 300 patients. Eur J Cardiothorac Surg. 2008;33(4):554-9.

22. Bozbuga N, Erentug V, Erdogan HB, Kirali K, Ardal H, Tas S, et al. Surgical treatment of aortic abscess and fistula. Tex Heart Inst J. 2004;31(4):382-6.

23. Borger MA, Prasongsukarn K, Armstrong S, Feindel CM, David TE. Stentless aortic valve reoperations: a surgical challenge. Ann Thorac Surg. 2007;84(3): $737-44$.

\section{Ready to submit your research? Choose BMC and benefit from:}

- fast, convenient online submission

- thorough peer review by experienced researchers in your field

- rapid publication on acceptance

- support for research data, including large and complex data types

- gold Open Access which fosters wider collaboration and increased citations

- maximum visibility for your research: over $100 \mathrm{M}$ website views per year

At BMC, research is always in progress.

Learn more biomedcentral.com/submissions 